\title{
The impact of a community trial on the pharmacological treatment in the individuals with the metabolic syndrome: findings from the Isfahan Healthy Heart Program, 2001-2007
}

\author{
Mojgan Gharipour ${ }^{1}$, Roya Kelishadi ${ }^{1}$, Alireza Khosravi², Shahin Shirani², Mohsen Masjedi², \\ Nizal Sarrafzadegan ${ }^{1}$
}

${ }^{1}$ Isfahan Cardiovascular Research Institute, Isfahan University of Medical Sciences, Isfahan, Iran

2Hypertension Research Center, Isfahan University of Medical Sciences, Iran

${ }^{3}$ Department of Immunology, Isfahan University of Medical Sciences, Iran

\author{
Submitted: 6 December 2010 \\ Accepted: 30 April 2011
}

Arch Med Sci 2012; 8, 6: 1009-1017

DOI: 10.5114 /aoms.2012.32407

Copyright @ 2012 Termedia \& Banach

\author{
Corresponding author: \\ Mohsen Masjedi PhD \\ Department of Immunology \\ Faculty of Medicine \\ Isfahan University \\ of Medical Sciences \\ Postcode: 8174673461 \\ Isfahan, Iran \\ Phone: +983117922416 \\ Fax: +983117922431 \\ E-mail: masjedi@med.mui.ac.ir
}

\begin{abstract}
Introduction: Pharmacological therapy is a crucial step in the management of individuals with the metabolic syndrome, when lifestyle modifications alone cannot achieve the therapeutic goals. The present study aimed to evaluate the efficacy of comprehensive interventions with the pharmacological treatment in individuals with the metabolic syndrome.

Material and methods: A cross-sectional population-based survey examined a sample of adults before and after conducting a community trial. Physical examination and blood sampling, data regarding the demographic characteristics, medical status and history of medication use were obtained. Pharmacologic treatment related to metabolic syndrome's components was also determined. Results: The most common pharmacologic agents consumed by individuals with metabolic syndrome were $\beta$-blockers (26.1\% and 30.4\% in 2001 and 2007, respectively), followed by lipid-lowering agents (5.4\% and 14\% in 2001 and 2007, respectively), with significant differences before and after intervention. The prevalence of metabolic syndrome was higher in women than in men both before ( $36.4 \%$ vs. $14 \%)$ and after the community trial $(26.1 \%$ vs. $16 \%$, respectively) in the intervention areas $(p<0.001)$.

Conclusions: We found a significant increase in medication use to control blood pressure and dyslipidemia among the individuals with the metabolic syndrome, notably in the intervention areas. In addition to the population approach, the highrisk approach should be considered in community trials for prevention and control of non-communicable diseases.
\end{abstract}

Key words: metabolic syndrome, pharmacological treatment, community trial, Iran.

\section{Introduction}

The metabolic syndrome is a great public health concern, and patients with this cluster of risk factors are at significantly increased risk of developing diabetes and cardiovascular disease (CVD) [1]. This condition is highly prevalent in both developed and developing countries and carries a risk of diabetes, cardiovascular morbidity and mortality [2]. The metabolic syndrome has recently aroused universal attention from the scientific societies and healthcare managers [3]. The main goal of treatment for the metabolic 
disease is to reduce cardiovascular risk [4]. Components of the metabolic syndrome that need control are atherogenic dyslipidemia, elevated blood pressure, elevated fasting glucose, prothrombotic factors, and proinflammatory state [4]. Pharmacological therapy is a critical step in the management of subjects with the metabolic syndrome when lifestyle modifications fail to achieve the therapeutic goals [5].

In addition to weight loss, there is no single best therapy, and the treatment should consist of treatment of the individual components of the metabolic syndrome [6]. Although lifestyle change is the first line of therapy, medical treatment is usually needed for the optimal control [7].

A recent community-based interventional program, named the Isfahan Healthy Heart Program (IHHP), is a community-based interventional program for CVD and control of related risk factors. The goal of the IHHP study was to make a strategic shift towards prevention and control of noncommunicable diseases (NCDs) and their risk factors and promote healthy lifestyles by using comprehensive population and high-risk approaches to prevention [8]. Several interventional trials have reported the effects of lifestyle intervention programs among the high-risk populations [9]. However, the pooled effects suggest that multiple risk factor intervention has no effect on mortality. In spite of recent meta-analyses there is doubt about whether lifestyle interventions actually help to reduce the cardiovascular disease risk factors [10].

The present study aimed to evaluate the efficacy of IHHP on drug compliance in the individuals with the metabolic syndrome after comprehensive intervention in both sexes in an intervention area compared with a reference area. The hypothesis for intervention was that participants in the intervention area would achieve greater compliance in the management of the metabolic syndrome components than found in the reference area.

\section{Material and methods}

The Isfahan Healthy Heart Program, a comprehensive integrated community-based action-oriented study with a reference community, has been conducted by the Isfahan Cardiovascular Research Centre since 2001 to 2007 [11]. Two intervention counties (Isfahan and Najafabad) and a reference area (Arak), all located in the central part of Iran, were included in the study. According to the 2000 National Census, the population was 1,895,856 in Isfahan and 275,084 in Najafabad - a county neighboring Isfahan. Arak, located $375 \mathrm{~km}$ North-West of Isfahan, with a population of 668,531 , was selected as a reference area because of socioeconomic, demographic and health profile similarities to the intervention areas. In each community, a random inde- pendent sample of adults was selected by multistage cluster sampling. Clusters were chosen from three counties in the central part of Iran, based on their demographic and socioeconomic characters. The effect of confounding has been addressed by using random, stratified household sampling, based on age and sex groups. The IHHP was conducted as three phases: the situational analysis or baseline phase, the second or implement interventional activities in the interventional area, and the last phase or outcome evaluation phase. During the second phase, we carried out an organized approach to program evaluation including each activity (i.e. process evaluation) and program annual monitoring (i.e. impact evaluation).

The participants were more than 19 years old. The samples underwent a 30-minute interview to complete validated questionnaires containing questions on demography, socioeconomic status, smoking behavior, physical activity, nutritional habits and other behavior regarding CVD [12].

Written informed consent was obtained from subjects after full explanation of the procedure. The study was approved by the Ethics Committee of the Isfahan Cardiovascular Research Center. IHHP was covered under IRB protocol FW A00008578 and was performed at the Isfahan Cardiovascular Research Center with the collaboration of Arak University. The details of the program, inclusion and exclusion criteria, have previously been reported elsewhere [11-13].

\section{Anthropometric measurements}

Waist circumference (WC) was measured the level of the umbilicus and recorded in centimeters using standard WHO methods [13].

\section{Biochemical measurements}

Blood lipids were measured enzymatically with the commercially available reagents (Cholesterol/HP, cat. no. 816302, and Triglycerides/GPO, cat. no. 816370, both from the Boehringer Mannheim). HDL cholesterol was measured in the clear supernatant after precipitating the other lipoproteins with heparin and $\mathrm{MnCl}_{2}(1.3 \mathrm{~g} / \mathrm{l}$ and $0.046 \mathrm{~mol} / \mathrm{l}$, respectively) and removing excess $\mathrm{Mn}^{2+}$ by precipitation with $\mathrm{NaHCO}_{3}$. Fasting glucose was measured using the Glucose Standard Assay (Sigma chemical, St Louis) [14].

\section{Metabolic syndrome definition}

The updated ATP-III definition of the metabolic syndrome was met when three or more of the following criteria were present: waist circumference $\geq 102 \mathrm{~cm}$ (40 inches) in men and $88 \mathrm{~cm}$ (35 inches) in women; $\mathrm{HDL}>1.03 \mathrm{mmol} / \mathrm{l}(40 \mathrm{mg} / \mathrm{dl})$ in men and $1.30 \mathrm{~mol} / \mathrm{l}(50 \mathrm{mg} / \mathrm{dl})$ in women or specific treatment for this lipid abnormality; triglycerides 
$\geq 1.7 \mathrm{mmol} / \mathrm{l}(150 \mathrm{mg} / \mathrm{dl})$ in men and women or specific treatment for this lipid abnormality; systolic blood pressure $\geq 130 \mathrm{~mm} \mathrm{Hg}$ or diastolic blood pressure $\geq 85 \mathrm{~mm} \mathrm{Hg}$ in men and women or treatment of previously diagnosed hypertension; and fasting glucose $\geq 5.6 \mathrm{mmol} / \mathrm{l}(100 \mathrm{mg} / \mathrm{dl})$ in men and women [15].

\section{Pharmacological treatment}

The pattern of medication use was defined by the drugs used to control and treat each component of metabolic syndrome, including chemical and herbal drugs, determined by validated questionnaire. Anti-hypertension drugs (e.g. calcium channel blocker, $\beta$-blocker and angiotensin-converting enzyme (ACE) inhibitors) were considered relevant. Insulin resistance treatment drugs such as, thiazolidinediones, and statins for dyslipidaemia were taken into account. Aspirin was recommended by physicians for primary prevention of prothrombotic factors and the proinflammatory state in patients with the metabolic syndrome. We asked the participants about the herbal drugs, since the Iranian subjects are interested in using the herbal drugs for different health disorders including dyslipidemia, hypertension and hyperglycemia.

\section{Statistical analysis}

Results are reported as mean \pm standard deviation (SD). An independent $t$-test was used to examine the difference between the quantitative variables, and a $\chi^{2}$ test was used to examine the difference between the qualitative variables in individuals with or without the metabolic syndrome according to sex. $P$ of 0.05 or less was considered statistically significant. Logistic regression was conducted to assess the determinants of the pharmacological treatment among subjects with the metabolic syndrome before and after interventions. Antihypertensive, diabetes drugs and lipid-lowering agents were entered in the model to estimate their independent effects in each area and study phase. $P$ of $<0.05$ was considered to be statistically significant. All statistical analyses were performed using SPSS (SPSS Inc., Chicago, IL, USA) version 15.

\section{Results}

Total participants of IHHP in the intervention areas were 6175 in 2001, and 4719 in 2007 (the corresponding figures in the reference area were 6339 and 4853 , respectively). The number of the individuals with the metabolic syndrome in 2001 and 2007 was 1570 and 982 in the intervention areas, and 1245 and 973 in the reference areas. The prevalence of the metabolic syndrome was $25.5 \%$ in 2001 and $21.1 \%$ in 2007 in the intervention areas and $19.9 \%$ in 2001 and $20.2 \%$ in 2007 in the reference area $(p<0.05)$. The prevalence of the metabolic syndrome was higher in women than in men both before (36.4\% vs. $14 \%)$ and after the community trial ( $26.1 \%$ vs. $16 \%$, respectively) in the intervention areas $(p<0.001)$. The average age of individuals with the metabolic syndrome was $47.67 \pm 14.59$ years in women, and $49.75 \pm 15.25$ years in men $(p<0.001)$. In 2001 the mean age of women in the intervention and reference areas was $45.99 \pm 14.28$ and $47.95 \pm 14.4$, and in men $50.16 \pm 14.31$ and 49.98 \pm 14.58 , respectively $(p<0.001)$, while in 2007 , in women the mean age was $49.45 \pm 14.78$ and 48.48 \pm 14.92 and in men $49.83 \pm 15.66$ and $48.88 \pm 16.56$ in the intervention and reference areas, respectively. The minimum and maximum age was 19 and 89 years $(p<0.001)$.

Demographic data of participants are shown in Table I. The prevalence of abdominal obesity, hypertriglyceridemia and high blood pressure decreased significantly after intervention in both sexes and study areas, whereas the frequency of low HDL cholesterol increased significantly from 2001 to 2007 in both sexes and in both areas. Table II presents the number of patients for each category of recommended medications for the different components of the metabolic syndrome according to sex. Medications were categorized in five groups as antihypertensive, lipid-lowering, antidiabetic, aspirin and herbal. The most common single medication for control of hypertension was a $\beta$-blocker $(26 \%$ in 2001 and 34\% in 2007), without significant differences before and after intervention. The most common drug to control diabetes taken by the subjects in the intervention areas was glibenclamide, without a significant difference after interventions (females: 47.5\% in 2001 and 49.1\% in 2007; males: $43.6 \%$ in 2001 and $46.2 \%$ in 2007). Among lipidlowering agents statins were the least frequent medication used in males and females before intervention ( $2.9 \%$ and $1.1 \%$, respectively), whereas after intervention the total number of statin users was increased from $2.4 \%$ to $14 \%$ ( $p<0.001$ ). The total number of aspirin users was $8 \%$ in 2001 and $18.0 \%$ in 2007 ( $p<0.001)$. There was a significant difference in the use of herbal medicine before and after interventions; $8.3 \%$ of the participants used herbal medicine in 2001 and 18.0\% in 2007 ( $p<0.001$ ). After the IHHP interventions hypertension was managed more frequently by $\beta$-blockers (34\%) $(p<0.004)$ and diabetes with glibenclamide $(47.8 \%)$ $(p<0.699)$ than before the intervention. No significant difference was observed between males and females regarding the type of medications used. Table III shows the number of patients for each category of drugs for the different components of the metabolic syndrome according to sex in the references area. Our results showed that the rate of using $\beta$-blockers, ACE inhibitors, statins, metformin, and aspirin increased in the interven- 


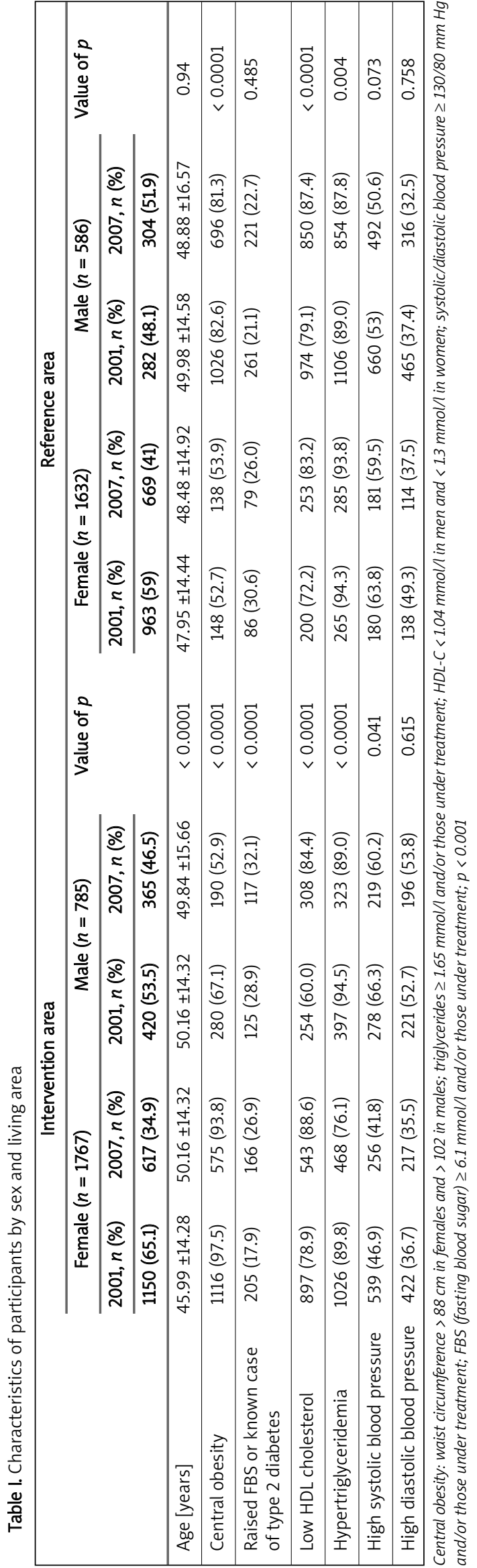

tion areas after intervention. Table IV shows the association of some variables with the pharmacological treatment in both the intervention and reference areas before and after interventions. Based on the logistic regression analysis, the male sex decreased the medication use 0.69-fold from 2001 to 2007 ( $p<0.001)$. The older subjects had approximately 8 times higher use of antihypertensive medications than the younger participants $(p<0.001)$. Education did not show a significant relationship with any type of drug in both the intervention and reference areas in 2001 and 2007.

Living in an urban area increased the rate of using lipid-lowering agents 1.85 -fold after interventions in the intervention areas $(p<0.05)$. In the intervention areas, the rate of using antidiabetic agents had not changed after interventions, based on age, sex and education, but living in an urban area increased this figure 2.7-fold from 2001 to 2007 in the intervention area among the study population $(p<0.05)$. Our results revealed a significant relationship between some social determinants and the pharmacological treatment among subjects with the metabolic syndrome between the intervention and reference areas from 2001 to 2007 ( $p<0.001)$.

\section{Discussion}

The present study aimed to evaluate the efficacy of IHHP on drug compliance in the individuals with the metabolic syndrome after comprehensive intervention in both sexes in an intervention area compared with a reference area. We found that after implementation of a community-based program, the pharmacologic treatment for the management of the different components of the metabolic syndrome increased significantly. These findings suggest that there is national interest in monitoring and managing the CVD risk factors in our population, and it seems that intensive educational programs with a high-risk approach might be successful in increasing the population awareness for screening and control of the CVD risk factors.

The prevalence of the metabolic syndrome is considerably high in Iran [18]. The IHHP study reported that in the urban Iranian populations, the ageadjusted prevalence of the metabolic syndrome was $10.7 \%$ in men and $35.1 \%$ in women [19]. The ageadjusted prevalence of the metabolic syndrome decreased from $23.3 \%$ to $21 \%$ in the intervention areas. However, it showed an insignificant increase from $19.9 \%$ to $20.2 \%$ in the reference area. Primary care physicians and cardiologists in the community practice are on the front lines, when it comes to battling the epidemic of the metabolic syndrome. The first item physicians need to measure the patient's size and the size of waistline at the first visit. Because obesity predisposes individuals to 


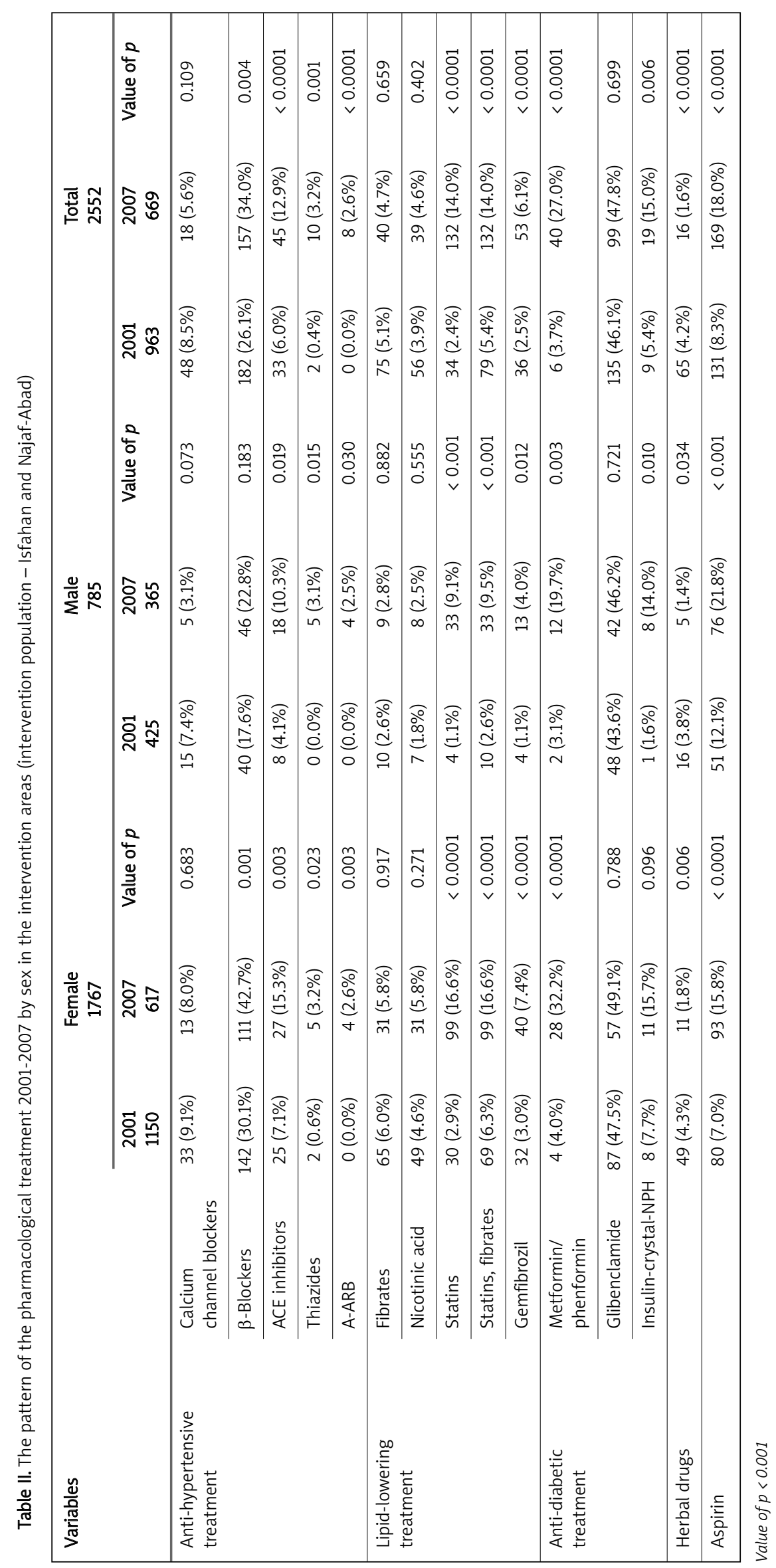




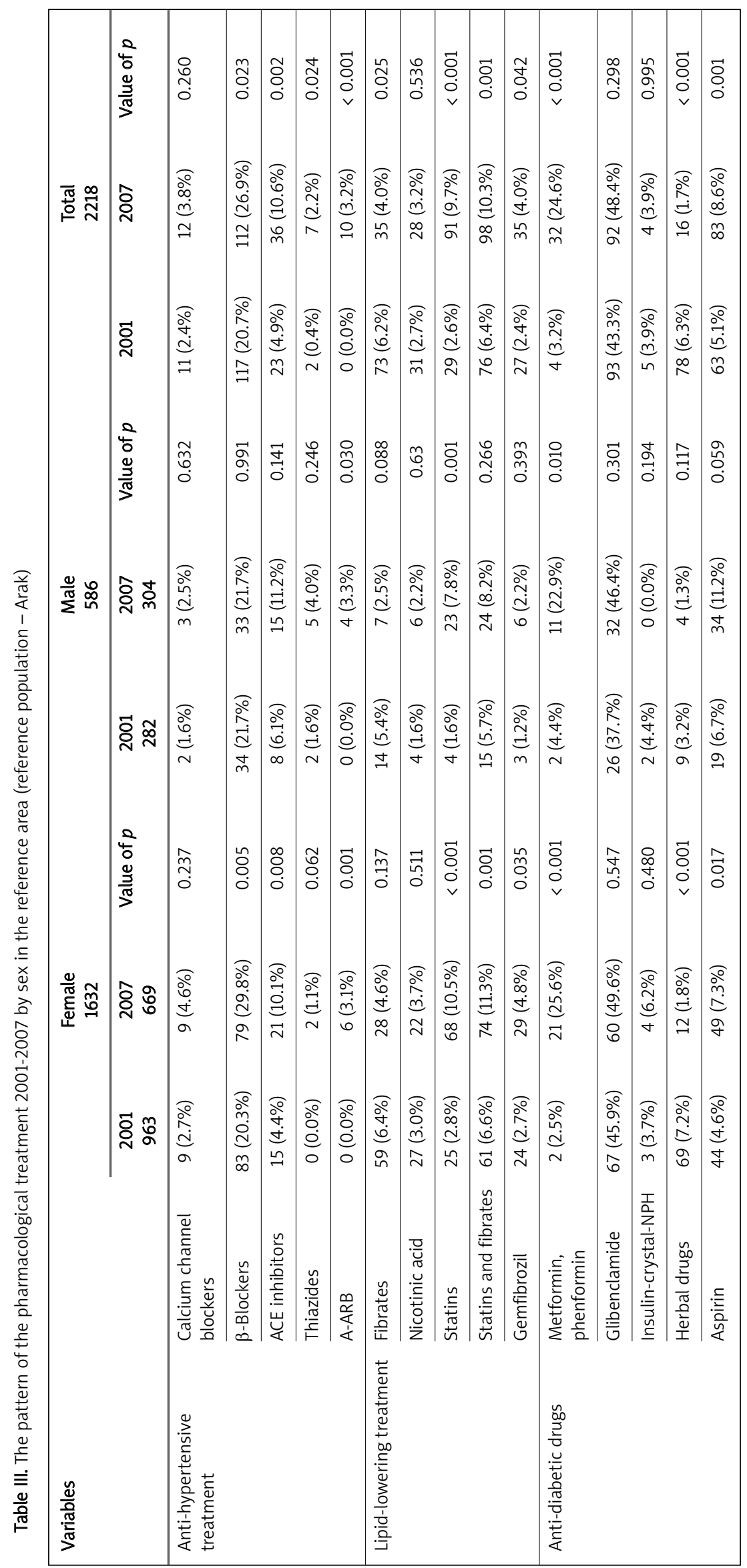


Table IV. The relationship between the pharmacological treatment and determinants in 2001-2007 by sex among subjects with the metabolic syndrome

\begin{tabular}{|c|c|c|c|c|c|c|}
\hline & & & $\begin{array}{l}\text { Anti-hypertensive } \\
\text { treatment }\end{array}$ & $\begin{array}{l}\text { Lipid-lowering } \\
\text { treatment }\end{array}$ & $\begin{array}{l}\text { Anti-diabetic } \\
\text { drugs }\end{array}$ & $\begin{array}{l}\text { Total } \\
\text { drugs }\end{array}$ \\
\hline \multicolumn{7}{|c|}{ Intervention } \\
\hline \multirow[t]{10}{*}{2001} & \multirow[t]{2}{*}{ Sex } & Female & - & - & - & - \\
\hline & & Male & $0.44(0.30-0.64)^{\star *}$ & $0.37(0.2-0.67)^{\star \star}$ & $0.82(0.49-1.36)$ & $0.66(0.49-0.89)^{\star \star}$ \\
\hline & \multirow[t]{3}{*}{ Education } & $0-5$ & - & - & - & - \\
\hline & & $6-12$ & $1.17(0.74-1.86)$ & $0.85(0.48-1.49)$ & $0.69(0.36-1.34)$ & $0.74(0.52-1.04)$ \\
\hline & & $>12$ & $1.41(0.51-3.88)$ & $0.52(0.12-2.24)$ & $1.94(0.4-9.33)$ & $0.69(0.34-1.43)$ \\
\hline & \multirow{3}{*}{$\begin{array}{l}\text { Age group } \\
\text { [years] }\end{array}$} & $19-39$ & - & - & - & - \\
\hline & & $40-59$ & $8.72(3.87-19.65)^{\star \star}$ & $3.2(1.73-5.92)^{\star *}$ & $1.01(0.47-2.16)$ & $5.97(3.91-9.15)^{\star \star}$ \\
\hline & & $\geq 60$ & $16.07(7.01-36.89)^{\star *}$ & $3.46(1.75-6.87)^{\star *}$ & $1.97(0.9-4.32)$ & $15.25(9.66-24.06)^{\star \star}$ \\
\hline & \multirow[t]{2}{*}{ Residency } & Urban & - & - & - & - \\
\hline & & Rural & $1.17(0.78-1.74)$ & $1.2(0.74-1.97)$ & $1.27(0.69-2.32)$ & $1.15(0.84-1.57)$ \\
\hline \multirow[t]{10}{*}{2007} & \multirow[t]{2}{*}{ Sex } & Female & - & - & - & - \\
\hline & & Male & $0.41(0.27-0.62)^{\star \star}$ & $0.55(0.35-0.86)^{\star *}$ & $0.81(0.46-1.41)$ & $0.69(0.51-0.96)^{*}$ \\
\hline & \multirow[t]{3}{*}{ Education } & $0-5$ & - & - & - & - \\
\hline & & $6-12$ & $1.41(0.86-2.33)$ & $0.71(0.51-1.05)$ & $0.83(0.43-1.6)$ & $0.88(0.62-1.26)$ \\
\hline & & $>12$ & $1.11(0.5-2.45)$ & $0.74(0.29-1.85)$ & $1.03(0.24-4.52)$ & $0.87(0.46-1.64)$ \\
\hline & \multirow{3}{*}{$\begin{array}{l}\text { Age group } \\
\text { [years] }\end{array}$} & $19-39$ & - & - & - & - \\
\hline & & $40-59$ & $3.54(1.76-7.11)^{\star \star}$ & $3.52(1.82-6.78)^{\star \star}$ & $1.65(0.62-4.36)$ & $3.9(2.49-6.12)^{\star \star}$ \\
\hline & & $\geq 60$ & $7.24(3.51-4.94)^{\star \star}$ & $4.65(2.31-9.35)^{\star \star}$ & $1.1(0.42-2.9)$ & $10.5(6.42-17.17)^{\star \star}$ \\
\hline & \multirow[t]{2}{*}{ Residency } & Urban & - & - & - & - \\
\hline & & Rural & $0.58(0.34-0.99)^{*}$ & $0.54(0.29-0.99)^{\star}$ & $0.37(0.16-0.89)^{\star}$ & $0.45(0.29-0.7)^{\star \star}$ \\
\hline \multicolumn{7}{|c|}{ Reference } \\
\hline \multirow[t]{10}{*}{2001} & \multirow[t]{2}{*}{ Sex } & Female & - & - & - & - \\
\hline & & Male & $0.99(0.64-1.56)$ & $0.8(0.44-1.45)$ & $0.67(0.37-1.22)$ & $1.19(0.85-1.67)$ \\
\hline & \multirow[t]{3}{*}{ Education } & $0-5$ & - & - & - & - \\
\hline & & $6-12$ & $1.24(0.62-2.48)$ & $0.73(0.34-1.6)$ & $1.55(0.62-3.86)$ & $1.03(0.64-1.66)$ \\
\hline & & $>12$ & $1.77(0.61-5.15)$ & $0.93(0.21-4.09)$ & $2.36(0.35-15.73)$ & $1.45(0.63-3.36)$ \\
\hline & \multirow{3}{*}{$\begin{array}{l}\text { Age group } \\
\text { [years] }\end{array}$} & $19-39$ & - & - & - & - \\
\hline & & $40-59$ & $4.47(1.78-11.2)^{\star \star}$ & $2.18(1.11-4.28)^{\star}$ & $2.94(1.03-8.36)^{\star}$ & $4.91(2.97-8.09)^{\star \star}$ \\
\hline & & $\geq 60$ & $7.02(0.36-0.92)^{\star \star}$ & $2.27(1.08-4.73)^{\star}$ & $4.73(1.56-14.29)^{\star \star}$ & $10.2(6.02-17.27)^{\star \star}$ \\
\hline & \multirow[t]{2}{*}{ Residency } & Urban & - & - & - & - \\
\hline & & Rural & $0.57(0.36-0.92)^{*}$ & $0.74(0.43-1.27)$ & $0.86(0.44-1.67)$ & $0.68(0.48-0.95)^{\star}$ \\
\hline \multirow[t]{10}{*}{2007} & \multirow[t]{2}{*}{ Sex } & Female & - & - & - & - \\
\hline & & Male & $0.76(0.49-1.17)$ & $0.7(0.42-1.16)$ & $0.79(0.43-1.47)$ & $0.95(0.68-1.33)$ \\
\hline & \multirow[t]{3}{*}{ Education } & $0-5$ & - & - & - & - \\
\hline & & $6-12$ & $0.95(0.46-1.97)$ & $0.92(0.48-1.76)$ & $1.06(0.46-2.45)$ & $0.77(0.48-1.24)$ \\
\hline & & $>12$ & $1.96(0.49-7.82)$ & $0.48(0.06-3.87)$ & $5.78(0.55-60.72)$ & $1.34(0.51-3.55)$ \\
\hline & \multirow{3}{*}{$\begin{array}{l}\text { Age group } \\
\text { [years] }\end{array}$} & 19-39 & - & - & - & - \\
\hline & & $40-59$ & $2.15(1.08-4.27)^{*}$ & $2.63(3.84-10.72)^{\star *}$ & $2.48(0.98-6.3)$ & $3.06(1.98-4.74)^{\star \star}$ \\
\hline & & $\geq 60$ & $3.14(1.57-6.27)^{\star \star}$ & $2.58(1.28-5.21)^{\star \star}$ & $2.16(0.81-5.77)$ & $5.47(3.41-8.78)^{\star \star}$ \\
\hline & \multirow[t]{2}{*}{ Residency } & Urban & - & - & - & - \\
\hline & & Rural & $0.75(0.5-1.12)$ & $0.51(0.33-0.79)^{* *}$ & $0.68(0.37-1.25)$ & $0.62(0.46-0.85)^{\star \star}$ \\
\hline
\end{tabular}

${ }^{*} p<0.05,{ }^{* *} p<0.001$ 
several risk factors that comprise the metabolic syndrome [20].

Community interventions in the IHHP program were designed to improve the lifestyle indicators and behavior among the high-risk groups. Our previous studies showed that the improvement in nutritional habits, smoking and physical activity was significantly higher in the high-risk population, such as individuals with the metabolic syndrome, in the interventional areas compared to the reference area [8]. The IHHP holds comprehensive training courses and effective Continuing Medical Education (CME) programs in order to increase the attitude, knowledge and practice related to the cardiovascular disease risk factors among the health professionals including cardiologists, internists, general physicians, and nurses. Continuing Medical Education could help greatly to increase the knowledge and practice in the health professionals. Prevention, early detection, improved management of cardiovascular disease, as well as improvement in healthy lifestyle were our training goals [21].

The strength of the study is that patients and physicians were not trained about the metabolic syndrome and its components in 2001, whereas during IHHP interventions, health professionals underwent extensive training about the lifestyle modification, drug compliance, monitoring and control of CVD risk factors. Given the multiplicity of comprehensive training programs, IHHP has apparently increased drug acceptance in individuals with the metabolic syndrome. We suggest that the increased medication use, has resulted from the improved knowledge about the risk factor control and optimum medication use.

In this study, the most common pharmacologic agents consumed by individuals with the metabolic syndrome were, $\beta$-blockers $(26.1 \%$ and $30.4 \%$ in 2001 and 2007, respectively), followed by lipid-lowering agents (5.4\% and 14\% in 2001 and 2007), with significant differences before and after intervention. On one hand, the prevalence of hypertension was decreased significantly among both sexes from 2001 to 2007 , and on the other hand, the percentages of all types of hypertensive drugs, especially $\beta$-blockers, increased significantly from 2001 to 2007. It is supposed that on one hand, as hypertension is one of the most common risk factors among our study subjects, the use of antihypertensive drugs is significantly higher than other types of treatment. On the other hand, our population has higher awareness and practice as regards control and treatment of hypertension [22]. This is in line with another study in our population showing that $\beta$-blockers were the most prevalent anti-hypertensive drug used by the Iranian hypertensive patients [23]. However, it is established that most $\beta$-blockers have adverse effects on insulin sensitivity and carbohy- drate and lipid metabolism, and are not recommended in the metabolic syndrome. However, it seems that in Iran, most subjects with the metabolic syndrome have been treated for the individual risk factors. Furthermore, the new generation of $\beta$-blockers, such as carvedilol and nebivolol, have better effects on metabolism [24].

Lifestyle interventions are crucial for the control and management of major risk factors in the metabolic syndrome, but pharmacological interventions to specifically target all the risk factors are crucial as well. The focus on the individual risk factor medication involves a multipronged strategy to control the borderline high LDL cholesterol (statins, statinezetimibe combination); high triglycerides (fibrates, fibrate-statin combination, omega-3 fatty acids); low HDL cholesterol (niacin, fibrates); high blood pressure (ACE inhibitors, angiotensin receptor blockers, $\beta$-blockers, and others); and insulin resistance (metformin, acarbose, thiazolidinediones). However, population-based lifestyle interventions are critical, and are the best evidence-based approaches in the Iranian populations as well as South Asian [22-30]. Our results revealed a significant relationship between some social determinants and pharmacological treatment among subjects with the metabolic syndrome between the intervention and reference areas from 2001 to 2007. We found that the rate of treatment increased among the older females with a low level of education who lived in an urban area from 2001 to 2007.

Our results also showed that this community trial succeeded in increasing the pharmacologic treatment among individuals with metabolic syndrome in the intervention areas, whereas the reference population did not follow the same pattern.

This study relies on two sets of cross-sectional data to test hypotheses in the different study phases; thus we cannot conclude about just personal compliance. Finally, we could not determine the comorbid factors affecting individuals with the metabolic syndrome over time.

In conclusion, our results revealed a significant increase in the pharmacologic treatment to control blood pressure and lipid profile among the individuals with the metabolic syndrome. In addition to the population approach, the high-risk approach should be considered in community trials for prevention and control of non-communicable diseases.

Further research is needed to evaluate the impact of community trials on control and prevention of CVD risk factors and compliance behavior of patients who have been diagnosed with the metabolic syndrome.

\section{Acknowledgments}

This study was part of the Isfahan Healthy Heart Program that was supported by Grant No. 31309304 
from the Iranian Budget and Programming Organization in the Department of Health, Ministry of Health and Medical Education, Isfahan Cardiovascular Research Centre and the Isfahan Provincial Health Centre, both affiliated to the Isfahan University of Medical Sciences. The authors would like to acknowledge the editorial assistance of Dr. Belinda Peace.

\section{References}

1. Tankova TI, Chakarova NV, Dakovska LN, Kalinov KB, Atanassova IA. Assessment of the risk for metabolic syndrome in prediabetes and newly-diagnosed type 2 diabetes. J Diabetol 2010; 2: 1-5.

2. Yusuf S, Reddy S, Ounpuu S, Anand S. Global burden of cardiovascular diseases. Part II: variations in cardiovascular disease by specific ethnic groups and geographic regions and prevention strategies. Circulation 2000; 104: 2855-64.

3. Lopes N, Zanini AC, Casella-Filho A, Chagas AC. Metabolic syndrome patient compliance with drug treatment. Clinics (Sao Paulo) 2008; 63: 573-80.

4. Grundy SM, Cleeman JI, Daniels SR, et al.; American Heart Association; National Heart, Lung, and Blood Institute. Diagnosis and management of the metabolic syndrome: an American Heart Association/National Heart, Lung, and Blood Institute Scientific Statement. Circulation 2005; 112: 2735-52.

5. Deedwania PC, Gupta R. Management issues in the metabolic syndrome. J Assoc Physicians India 2006; 54: 797-810.

6. Third Report of the National Cholesterol Education Program (NCEP) Expert Panel on Detection, Evaluation, and Treatment of High Blood Cholesterol in Adults (Adult Treatment Panel III) final report. Circulation 2002; 106: 3143-421.

7. Bertrais S, Beyeme-Ondoua JP, Czernichow S, Galan P, Hercberg S, Oppert JM. Sedentary behaviors, physical activity, and metabolic syndrome in middle-aged French subjects. Obes Res 2005; 13: 936-44.

8. Baghaei A, Sarrafzadegan N, Rabiei K, et al. How effective are strategies for non-communicable disease prevention and control in a high risk population in a developing country? Isfahan Healthy Heart Programme. Arch Med Sci 2010; 6: 24-31.

9. Grundy SM. Primary prevention of coronary heart disease: integrating risk assessment with intervention. Circulation 1999; 100: 988-98.

10. Chobanian AV, Hill M. National Heart, Lung, and Blood Institute Workshop on Sodium and Blood Pressure: a critical review of current scientific evidence. Hypertension 2000; 35: 858-63.

11. Sarraf-Zadegan N, Sadri G, Malek Afzali H, et al. Isfahan Healthy Heart Programme: a comprehensive integrated community-based programme for cardiovascular disease prevention and control. Design, methods and initial experience. Acta Cardiol 2003; 58: 309-20.

12. Sarrafzadegan N, Kelishadi R, Esmaillzadeh A, et al. Do lifestyle interventions work in developing countries? Findings from the Isfahan Healthy Heart Program in the Islamic Republic of Iran. Bull World Health Organ 2009; 87: 39-50.

13. Sarraf-Zadegan N, Sadri G, Malek Afzali H, Baghaei M, Mohammadi Fard N, Shahrokhi S. Isfahan Healthy Heart Program: evaluation of comprehensive, community- based interventions for non-communicable disease. Prev Control J 2006; 2: 73-84.

14. Sarrafzadegan N, Kelishadi R, Baghaei A, et al. Metabolic syndrome: an emerging public health problem in Iranian women: Isfahan Healthy Heart Program. Int J Cardiol 2008; 131: 90-6.

15. Ford ES, Giles WH, Dietz WH. Prevalence of the metabolic syndrome among US adults: findings from the third National Health and Nutrition Examination Survey. JAMA 2002; 287: 356-9.

16. Agrawal V, Shah A, Rice C, Franklin BA, McCullough PA. Impact of treating the metabolic syndrome on chronic kidney disease. Nat Rev Nephrol 2009; 5: 520-8.

17. Expert Bianchi C, Penno G, Romero F, Del Prato S, Miccoli R. Treating the metabolic syndrome. Rev Cardiovasc Ther 2007; 5: 491-506.

18. Delavari A, Forouzanfar MH, Alikhani S, Sharifian A, Kelishadi R. First nationwide study of the prevalence of the metabolic syndrome and optimal cutoff points of waist circumference in the Middle East: the national survey of risk factors for noncommunicable diseases of Iran. Diabetes Care 2009; 32: 1092-7.

19. Gharipour M, Kelishadi R, Toghianfar N, et al. Pharmacological treatment of cardiovascular risk factors in individuals with metabolic syndrome: findings from Isfahan Healthy Heart Program. African J Pharm Pharmacol 2011; 5: 311-6.

20. Deedwania PC, Gupta R. Management issues in the metabolic syndrome. JAPI 2006; 54: 797-810.

21. Fordis M, King JE, Ballantyne CM, et al. Comparison of the instructional efficacy of internet-based CME with live interactive CME workshops: a randomized controlled trial. JAMA 2005; 294: 1043-51.

22. Khosravi A, Mehr GK, Kelishadi R, et al. The impact of a 6-year comprehensive community trial on the awareness, treatment and control rates of hypertension in Iran: experiences from the Isfahan healthy heart program. BMC Cardiovasc Disord 2010; 10: 61.

23. Khosravi A, Shirani S, Shahrokhi S, Mohammadifard N, Ansari R. Antihypertensive drugs used by hypertensive patients in the provincial cities of Isfahan, Najafabad and Arak. ARYA Atherosclerosis J 2006; 1: 275-80.

24. Carella AM, Antonucci G, Conte M, Di Pumpo M, Giancola A, Antihypertensive treatment with beta-blockers in the metabolic syndrome: a review. Antonucci Curr Diabetes Rev 2010; 6: 215-21.

25. Rabiei K, Kelishadi R, Sarrafzadegan N, Sadri G, Amani A. Short-term results of community-based interventions for improving physical activity: Isfahan Healthy Heart Programme. Arch Med Sci 2010; 6: 32-9.

26. Tavassoli AA, Gharipour M, Siadat ZD, Bahonar A, Sadry GH. Are obesogenic behavioral, socioeconomic and metabolic determinants different in Iranian men and women? J Health Popul Nutr 2010; 28: 602-9.

27. Kanjilal S, Shanker J, Rao V, Mukherjee M, lyengar SS, Kakkar V. Association of metabolic syndrome with atherothrombotic blood phenotypes in Asian Indian families with premature coronary artery disease. Arch Med Sci 2008; 4: 145-51.

28. Gluba A, Mikhailidis DP, Lip GY, Hannam S, Rysz J, Banach $M$. Metabolic syndrome and renal disease. Int J Cardiol 2012 [Epub ahead of print].

29. Barylski M, Małyszko J, Rysz J, Myśliwiec M, Banach M. Lipids, blood pressure, kidney - what was new in 2011? Arch Med Sci 2011; 7: 1055-66.

30. Bielecka-Dabrowa A, Aronow WS, Rysz J, Banach M. The rise and fall of hypertension: lessons learned from Eastern Europe. Curr Cardiovasc Risk Rep 2011; 5: 174-9. 